\title{
COMMENT
}

EVALUATION Experiments in moving beyond metrics are hard but worthwhile $\mathbf{p . 4 5 3}$
HISTORY What was the role of the Republic of Letters in economic growth? p.456
MICROBIOLOGY A life in search of our last common ancestor $\mathbf{p . 4 5 7}$
BREXIT Royal Society president on UK highereducation bill $\mathbf{p . 4 5 9}$

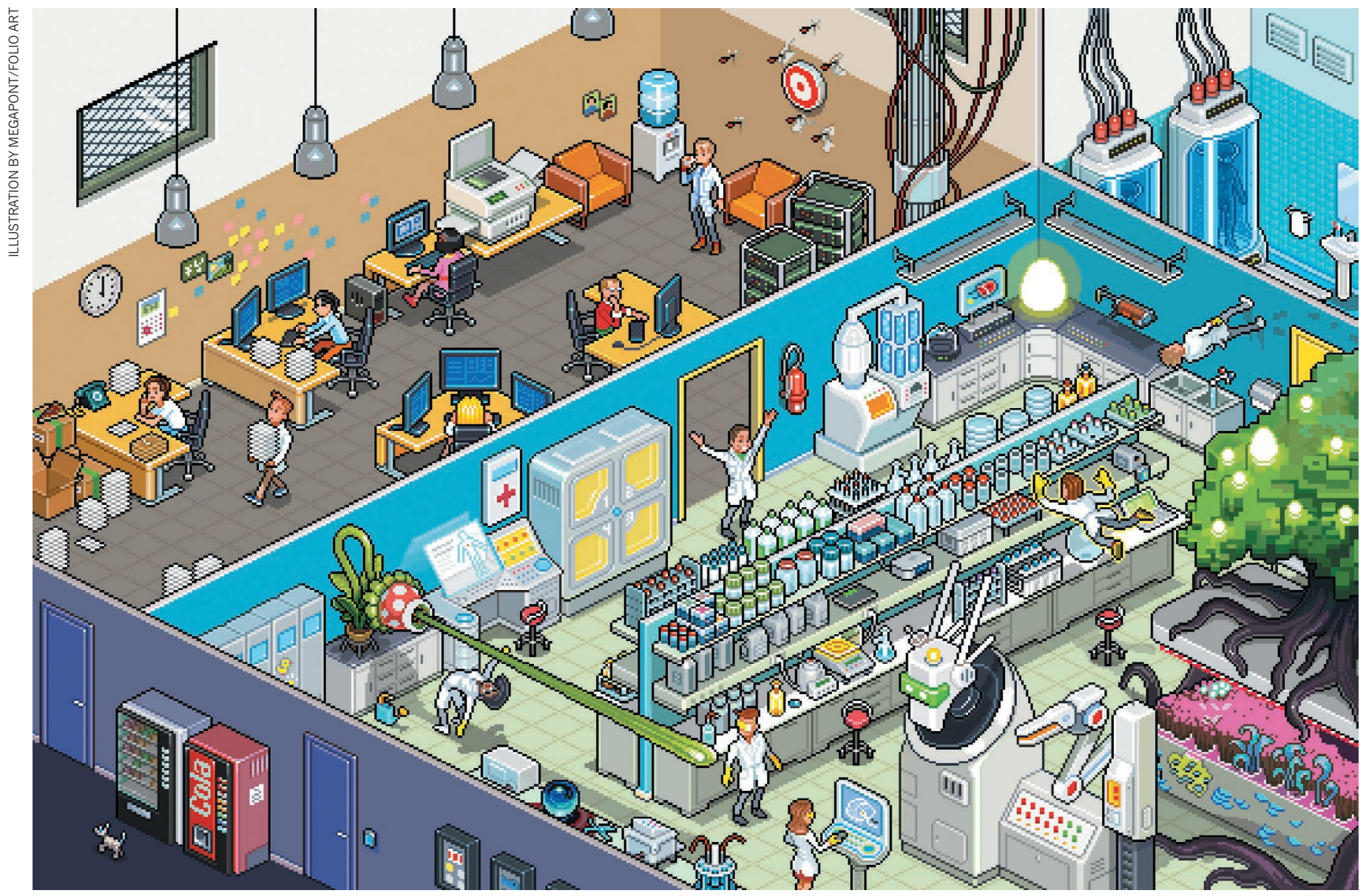

\section{Let researchers try new paths}

Demand for steady output stymies discovery. To pursue the most important research, scientists must be allowed to shift their focus, say Tolu Oni and colleagues.

$\mathrm{T}$ The scientific enterprise is stuck in a catch-22. Researchers are charged with advancing promising new questions, but receive support and credit only for revisiting their past work.

For example, while studying the epidemiology of HIV and tuberculosis, one of us (T.O.) realized that many people with these infectious diseases in urban areas also have non-infectious conditions, including hypertension and obesity. Hardly anyone was examining how and why, or investigating strategies for integrated prevention and management. Her proposals to research these topics were not well received by peer reviewers, who commented that she had not asked such questions before.

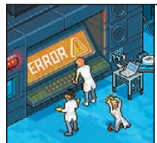

\section{YOUNG SCIENTISTS}

A Nature special issue

nature.com/youngscientists
We, the authors of this Comment, met earlier this year, having been selected by the World Economic Forum as part of a group of scientists under the age of 40 who "play a transformational role in integrating scientific knowledge into society for the public good". Through hours of discussion, we realized that we share many challenges, despite the recognition we have achieved and the diverse disciplines and geographical regions we represent. Most striking are the barriers to 
$>$ achieving impact. Our research often led us to questions that had greater potential than our original focus, typically because these new directions encompassed the complexities of society. We realized that changing tack could lead to more important work, but the policies of research funders and institutions consistently discourage such pivots.

\section{SHACKLED TO THE PAST}

When reviewers assess grants or academic performance, they focus largely on track records in a particular field. Young scientists, who must focus on developing their careers, are thus discouraged from exploration. Our own experiences provide a glimpse of the well-intentioned forces that can keep researchers from trying other paths (see 'Four tales of turning').

This challenge is not new. Physicistturned-structural biologist Venkatraman Ramakrishnan, who is president of the Royal Society, worked for several years in a job with funding that was contingent on a steady stream of publications. This forced him to ask safe but incremental questions. To pursue what became his Nobel-prizewinning work (on the structure of the ribosome), he moved to another institution where he could ask the questions that interested him, irrespective of the chances for publication. As he describes in his Nobel biography, the decision required an international move and a large pay cut.

For every story like this, there are too many where investigators have made a rational choice not to pursue areas outside

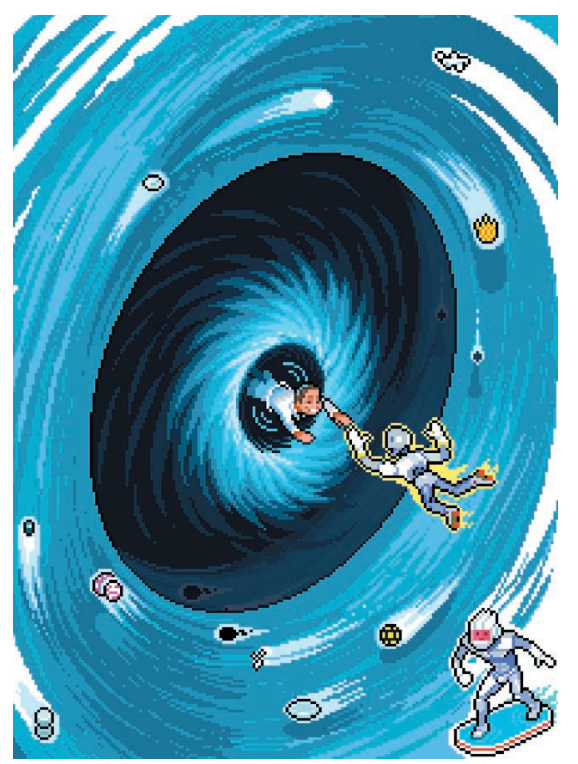

their core expertise. We spend so much effort trying to find our way that we risk losing the drive to apply skills to the broader world, and stick instead to the less-fulfilling security of 'productivity'.

More bold is Eva Alisic, a psychologist and senior research fellow at Monash University Accident Research Centre in Victoria, Australia. Earlier this year, Alisic began studying how refugee children from places such as Syria cope with trauma. Her institute has supported her so far, but this research is not the safest choice for a conventional career trajectory. She told us that she would rather give up an academic career than end this line of study. If we feel that we must leave academia to better contribute to society, the scholarly endeavour is compromised.

\section{GAINING FREEDOM}

We are not saying that scientists should dabble. Executing a pivot should still require conviction and risk, but the current strictures are too tight. Enabling early-career researchers to change trajectories is necessary to encourage the highest-impact research. Theories of brain plasticity and team productivity support this. Alongside specialization, diverse and varied experiences foster discoveries and promote the decision-making skills that are needed to lead research (C. S. Green \& D. Bavelier Psychol. Aging 23, 692-701; 2008).

Grant programmes do exist in some parts of the world to promote highly innovative projects for promising early- and mid-career researchers. Examples include the European Research Council's Starting and Consolidator grants and the International Research Scholars programme, which is jointly funded by the Howard Hughes Medical Institute, the Bill \& Melinda Gates Foundation, the Wellcome Trust and the Calouste Gulbenkian Foundation.

These pockets of funding are not enough. In 2015, the US National Institutes of Health (NIH) awarded 78 grants specifically for high-risk research. That same year, it gave out more than 15,000 conventional awards. These are typically granted to applicants with strong preliminary data in fields
Young scientists are warned that exploring new ideas could endanger their careers. Here, the authors share the challenges they faced.

Gerardo Adesso: I had expertise in quantum information theory, but was attracted to broader and more fundamental questions at the border between classical and quantum mechanics. These interests got a lukewarm reception in a national funding landscape biased towards applied research. I got funding only from unconventional organizations, such as the Foundational Questions Institute (www.fqxi.org). Soon, I had a series of highimpact publications and was rewarded with a substantial follow-up grant from the European Research Council, along the lines I had previously struggled to find support for.

Rob Knight: When setting up my lab, colleagues advised me to focus on one microbe rather than the ecosystem of gut flora. My work on Salmonella was topical and thought to have excellent potential for federal funding - a sound investment of my start-up funds. One of my first graduate students, Cathy Lozupone, cemented my decision to pivot, against the advice of evaluation committees and senior colleagues. We both knew it was a gamble, but she opted to work on bioinformatics and phylogeny despite having no training in computer science. Her software, UniFrac, has now been cited more than 2,000 times, and microbiome research has become one of the fastest expanding areas of biomedical research.

Tolu Oni: To do urban health research, I needed to explore the field and engage with new sectors of academia, society and policy. I also needed training in spatial analytical tools to better investigate health inequalities and their urban determinants. But my lack of publications in the field made me less competitive for grants. I continued publishing on my infectious-diseases work amid criticism that my new focus was diluting my research record. A faculty position has offered support and flexibility to pursue this chosen focus, but work is slow.

Fabio Sciarrino: Since my PhD, I have worked on the foundations of quantum mechanics and experimental quantum optics. When I sought to use my expertise to develop technology, it was difficult. My goal was to design circuits based on light rather than on electricity; my grant applications on this idea were not funded. Reviewers doubted that the project was feasible. A new PhD student and I took a risk: we conducted a proof-ofprinciple demonstration of a quantum chip. This was key to the award of a grant from the European Research Council that allowed me to achieve breakthroughs in an area now considered a hot topic (see www.3dquest.eu). 
where they are already recognized as experts. Although it is logical to assess a researcher's body of work over time, universities, research councils and other funding bodies should create a formal mechanism that explicitly accommodates pivots. If candidates can provide a convincing case for their own credibility and for studying new questions, they should be able to get support.

\section{PIVOT TO SUCCEED}

Two simple changes could make a big difference.

Create a 'pivot narrative'. Funding applications should give researchers who are in the midst of a shift an opportunity to describe their rationale. The significance and potential of the proposed work should be assessed alongside the researcher's proven abilities for research in other fields. Alisic, for example, could explain how her work with young people sensitized her to a growing need for evidence-based interventions to treat trauma in children fleeing conflict.

\section{"Innovation} will be stifled by failing to invest in the best emerging scientists." A 'pivot narrative' would also explain dry spells and the lack of a track record in the proposed area. The simple step of adding a text box to an application form could expand scientists' willingness to explore, and help assessors to support such exploration.

Revise peer review. There is little to no emphasis on peer-review training. Equipping scientists with skills for more nuanced appraisal will help them to consider varied attributes, particularly how to address complex societal challenges and to evaluate broader interdisciplinary questions. This could eventually change institutional cultures.

The greatest risk is that innovation will be stifled by failing to invest in the best emerging scientists, who are approaching the peak of their creativity.

Tolu Oni is a public-health physician scientist at the University of Cape Town, Cape Town, South Africa. Fabio Sciarrino is associate professor of physics at the Sapienza University of Rome, and junior fellow at the International School for Advanced Studies Sapienza, Rome, Italy. Gerardo Adesso is professor of mathematical physics at the University of Nottingham, Nottingham, UK. Rob Knight is professor of paediatrics and of computer science and engineering at the University of California San Diego, La Jolla, California, USA.

e-mail:tolullah.oni@uct.ac.za

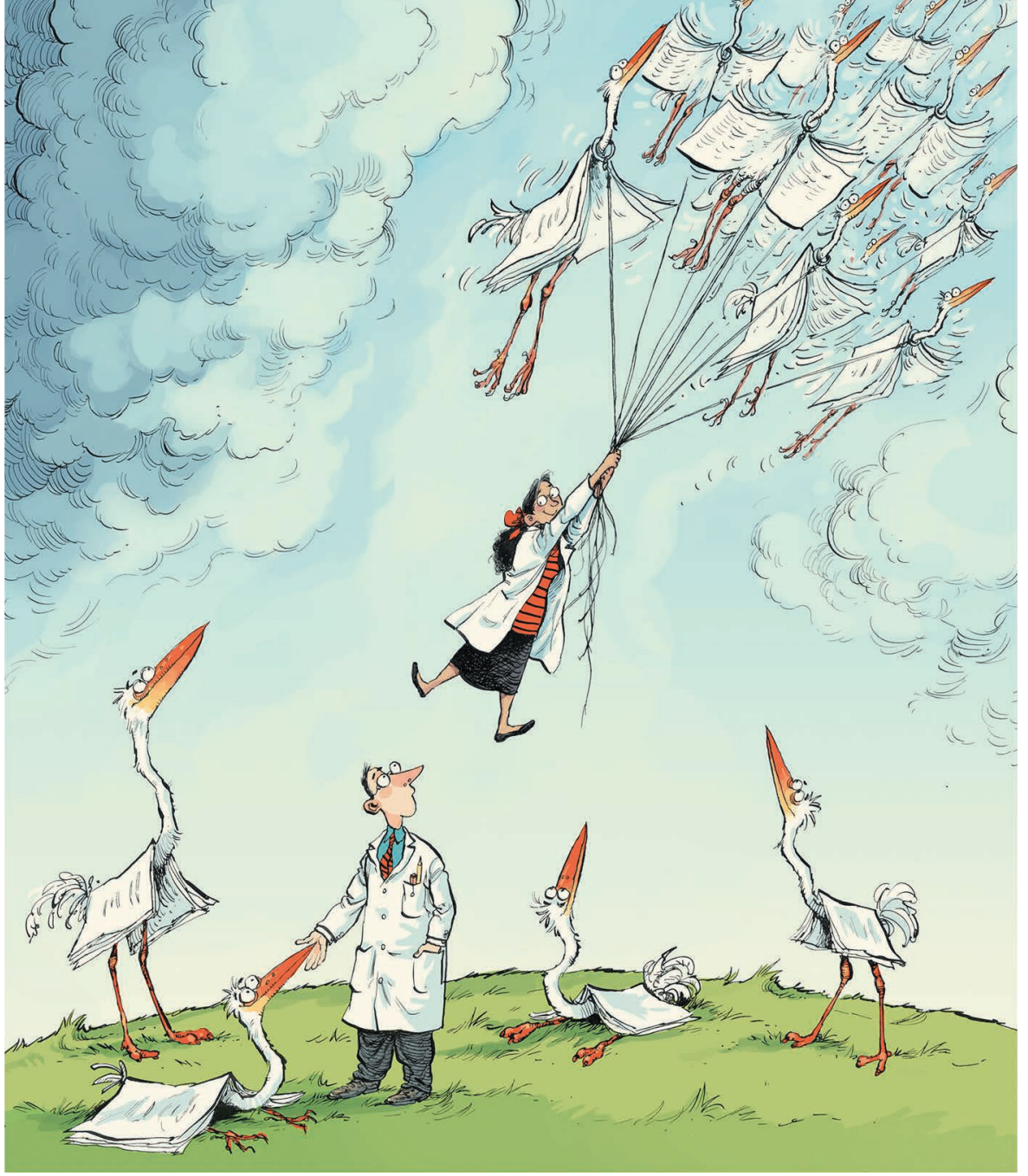

\section{Fewer numbers, better science}

REDEFINE EXCELLENCE Fix incentives to fix science

\section{Rinze Benedictus and} Frank Miedema

A n obsession with metrics pervades science. Our institution, the University Medical Center Utrecht in the Netherlands, is not exempt. On our website, we proudly declare that we publish about 2,500 peer-reviewed scientific publications per year, with higher than average citation rates.

A few years ago, an evaluation committee spent hours discussing which of several faculty members to promote, only to settle on the two who had already been awarded particularly prestigious grants. Meanwhile, faculty members who spent time crafting policy advice had a hard time explaining how this added to their scientific output, even when it affected clinical decisions across the country.

Publications that directly influenced patient care were weighted no higher in evaluations than any other paper, and $>$ 